\title{
Analysis of Formulated Cattle-Feed Samples for the Natural Occurrence of Storage Fungi and Aflatoxin B1
}

\author{
P. Jayaraman*, V. Rajesh and K. Vadamalai Krishnan \\ PG and Research Department of Botany, Government Arts College for Men (Autonomous) \\ Nandanam, Chennai 600 035, India \\ *Corresponding author
}

\section{A B S T R A C T}

\begin{tabular}{|l|}
\hline Ke y w o r d s \\
Cattle feed, \\
aflatoxin B1, \\
$\begin{array}{l}\text { Storage fungi, } \\
\text { Aspergillus, } \\
\text { Penicillium. }\end{array}$ \\
\hline Article Info \\
\hline $\begin{array}{l}\text { Accepted: } \\
\text { 25January } 2017 \\
\text { Available Online: } \\
\text { 10 February } 2017\end{array}$ \\
\hline
\end{tabular}

Contamination of feed materials with aflatoxins is an important issue due to both acute and chronic intoxication in animals and also harmful to humans. In the present study, 25 formulated cattle feed samples of different sources were collected from Tamil Nadu and analysed for moisture content, storage mycoflora including aflatoxigenic A. flavus and aflatoxin $\mathrm{B}_{1}$. The results show that the moisture content of the cattle feed samples varied from $7.0 \%$ to $14.6 \%$ with an average of $10.34 \%$. The storage fungi occurred in the range of 0 to $1,600 \mathrm{cfu} / \mathrm{g}$ with an average of $340 \mathrm{cfu} / \mathrm{g}$. Different species of storage fungi occurred in the cattle feed samples are A. glaucus, A. terreus, A. niger, Penicillium speices, A. flavus, A. fumiatus and A. candidus in the order of dominance. Among the species individual fungi, A. glaucus occurred frequently which is a remarkable incidence in the samples collected. Out of 25 samples analysed for the presence of aflatoxin $\mathrm{B}_{1}, 20$ were positive for aflatoxin $\mathrm{B}_{1}$ and 5 were negative. The quantity of aflatoxin $\mathrm{B}_{1}$ in cattle feed samples ranging from $5 \mathrm{ppb}$ to $60 \mathrm{pbb}$ with an average of $20 \mathrm{pbb}$. Out of $10 \mathrm{~A}$. flavus strains isolated 5 were found produced aflatoxin $B_{1}$. It is concluded that from the study as the majority of cattle feed samples analysed from the market is observed to be safe level for the contamination with aflatoxin $\mathrm{B}_{1}$ and storage fungi.

\section{Introduction}

Contamination of feeds with mycotoxins including aflatoxins accounts for significant economic losses in animal husbandry as well as in undesirable trade barriers for raw materials and consumable products $(\mathrm{Wu}$ 2006). The Food and Agriculture Organization (FAO) estimates that many basic food and feeds material could be contaminated with mycotoxin producing fungi, contributing to huge global losses, about 1000 million metric tons each year (Bhat, Rai, \& Karim, 2010). The occurrence of aflatoxins in feed materials also a major problem for farmers due to both acute and chronic intoxication in animals subsequently to human. The impact of feed contamination with mycotoxins includes productivity reduction and organ damage (Upadhaya, Park, \& Ha, 2010). The primary source of aflatoxins in cattle feed is due to the contamination of aflatoxin producing Aspergillus flavus in agricultural commodities including cereal grains and oilseeds such as rice, corn, peanuts, cottonseed, millet, sorghum and other feed grains which are main ingredients used for formulation of cattle and 
poultry. Aflatoxin is the most problematic in dairy due to its derivative aflatoxin M1 (AFM1) present in milk, and its potential health hazard for human consumption. The studies of contamination of aflatoxins in agricultural commodities like maize, rice, wheat and other crops including oilseeds like peanuts have been reported in many parts of India from various research Institutes (Oranusi and Olarewaju, 2013; Vasanthi et al., 2012; European Union, 2011; Reddy et al., 2008; Toteja et al, 2006; Bilgrami et al.,1980). The natural occurrence of aflatoxins in various feed materials were reported by Whitlow et al., (2016), Korrapati et al., (2015), Kangetha and Langa (2009), Johanna (2008) which indicate the contamination of aflatoxins is threat to health.

Mycotoxins are ubiquitous in agricultural commodities and produced by several fungi, particularly manyspecies of Aspergillus, Fusarium, Penicillium, Claviceps and Alternaria etc. Natural occurrence of aflatoxins in raw agricultural products poses severe health and economic risks worldwide. The remarkable contamination of aflatoxin $\mathrm{B}_{1}$ in rice bran, de-oiled bran, Jatropha seeds, cattle-feed and $\mathrm{M}_{1}$ in milk were analysed in our earlier studies, which indicate health threatening in humans as well as animals (Jayaraman et al., 2011; Jayaraman and Kalyanasundarm, 2009; Jayaraman and Kalyanasundaram, 1994; Jayaraman, 1991; Jayaraman and Kalyanasudaram, 1990). The studies shows that among the species of mycotoxins producing fungi, Aspergillus flavus sub sp. parasiticus is a potent aflatoxin producing fungi occurred frequently in stored food grains, rice bran as well as in the freshly harvested grains before storage were reported (Jayaraman and Kalyanasundaram, 1994; Jayaraman and Kalyanasundaram, 1992; Jayaraman and Kalyanasundaram, 1990; Bhanumathy and Kalyanasundaram, 1986, Gajapathy and Kalyanasundaram, 1986;
Bilgrami et al., 1980;). The natural occurrence of aflatoxins in rice bran and its products indicates that the formulated cattle feed with rice bran may possible for the contamination with aflatoxin. The remarkable contamination of aflatoxin $B_{1}$ in rice bran, de-oiled bran and cattle-feed and $\mathrm{M}_{1}$ in milk were reported in our earlier studies (Jayaraman and Kalyanasundarm, 2009; Jayaraman and Kalyanasundaram, 1994), which indicate health threatening in humans as well as animals.

Based on the above study, the investigations, the present study is made for survey on contamination of aflatoxin $\mathrm{B}_{1}$ and storage fungi including toxigenic Aspergillus flavus in cattle-feed samples collected from different sources like local markets, and dairy farms of Tamil Nadu.

\section{Materials and Methods}

\section{Samples Collection}

The formulated cattle feed samples were collected from the markets, manufacturers and dairy farm from Chennai, Chengalpet, Kanchipuram, Maduranthagam, Vellore and Thiruvannamalai districts of Tamil Nadu. The samples were collected in $500 \mathrm{~g}$ quantity by random sampling method in preclened plythene bags and closed tightly with rubber brands. Then the samples were labelled properly for source, date of collection and place of collection and kept in plastic container in the laboratory for further analysis.

\section{Determination of Moisture Content}

The moisture content of the composite cattle feed samples were determined by hot-air oven drying method at $100^{\circ} \mathrm{C}$ temperature for 1 hour period. Exactly $5 \mathrm{~g}$ of cattle feed sample 
was taken for drying in oven and the loss of weight was calculated. The method was standardised till obtained same value of loss of weight by repeated drying. The percentage of moisture content of cattle feed samples were calculated and expressed on wet weight basis.

\section{Analysis of storage fungi}

The storage mycoflora of the cattle feed samples were analysed by using serial dilution plate technique. One $\mathrm{ml}$ aliquots of the serially diluted samples were plated aseptically over the agar medium and the plates were swirled to distribute the inoculum uniformly entire surface area. To enumerate the storage fungi which are usually grow after storage on agricultural raw materials for cattle feed formulation, a highly osmotic selective medium called Czapek's Dox Agar (CDA) (Rao \& Kalyanasundaram, 1983) containing $50 \%$ sucrose w/v sucrose was used throughout the study. The media included antibiotic streptomycin and penicillin in mentioned concentration to suppress any external contamination. Then the inoculated plates were incubated at $30+/-1{ }^{\circ} \mathrm{C}$ up to one week for development of fungal colonies. The individual species of storage fungi were observed separately and their numbers were expressed as colony forming units per gram (cfu/g) of cattle feed samples. The different species of Aspergillus and Penicillium were identified according to standard methods used (Jayaraman and Kalyanasundaram, 1994). The individual fungal species were also maintained on agar slants of normal Czapek's Dox Agar with 3\% sucrose for further work.

\section{Aflatoxin Analysis}

\section{TLC method}

The extraction, isolation and assay of aflatoxins from cattle feed samples were done by the simple screening method by Seitz and Mohr (1972) using methanol as a solvent and separation by Thin Layer Chromatrography. The sample spotted TLC plates were developed in chloroform : acetone (88:12) as a developing solvent. The identification of aflatoxin $\mathrm{B}_{1}$ was done using fluorescent UV lamp at short wave length (354 $\mathrm{nm})$. The presence of blue fluorescence is the indication of positive result. The samples were run along with standard aflatoxin $B_{1}$ for comparison. The quantitative estimation of the aflatoxin from samples was also made by the spectrophotometric method described by Nabney \& Nesbitt (1965). Aflatoxin recovered in cold methanol from silica gel plate was read spectrophotometerically at 363 $\mathrm{nm}$ and $420 \mathrm{~nm}$ and the OD values were taken for calculation. The following formula was used for quantitative estimation.

\section{ELISA method}

The in-house standard method of ELISA for determination of aflatoxin $B_{1}$ developed by ICRISAT, Hyderabad was used for further confirmation. The composite cattle feed samples were taken for extraction of aflatoxin by using solvents and the condensed samples containing aflatoxin if any is stored in small glass vials. Aflatoxin $\mathrm{B}_{1}$-BSA conjugate and aflatoxin $B_{1}$ antibodies were used for Enzyme Linked Immunoadsorbent assay of aflatoxins from samples. The micro-well ELISA plates containing 96 wells were used for reactions and the OD values were optically measured by microplate reader at $450 \mathrm{~nm}$. The OD values of the samples were compared with standard smples (aflatoxin $\mathrm{B}_{1} \quad$-BSA conjugate) and determined the results of samples.

\section{Test for Toxigenicity of Aspergillus flavus}

To screen the fungal isolates for production of aflatoxin in vitro, the fungi were cultured in 
slants of an agar medium containing $2 \%$ yeast extract and 15\% sucrose (YES). Toxins were extracted from the molten agar with chloroform and assayed by TLC using toluene: ethyl acetate: $90 \%$ formic acid (6:3:1) solvent system (Bullerman, 1974). The fluorescent spots in blue and green TLC under short wavelength indicates the presence or absence of aflatoxin and the toxigenic property of the Aspergillus flavus strains.

\section{Results and Discussion}

\section{Samples}

Totally 25 cattle feed samples were collected from different sources in markets and cattle farms of Kancheepuram, Thiruvallur, Villupuram, Thiruvannamalai and Vellore districts of Tamil Nadu. The cattle feed samples collected for the present study were belong to 8 different market brands available in dealers and cattle farms from respective manufacturers. All the samples were appeared in the form of compressed and dried pellets in various lengths of $2 \mathrm{~cm}$ to $5 \mathrm{~cm}$ with $0.5 \mathrm{~cm}$ breath. The details of samples were as Brand 1 (8 samples - Sample 1, 4, 10, 14, 19), Brand 2 (10 samples - Sample No. 3, 5, 7, 8, $11,12,13,18,23,24)$, Brand 3 ( 1 sample sample 2), Brand 4 (1 sample - sample 15), Brand 5 (1 sample - sample 16), Brand 6 ( 2 samples - 6, 17), Brand 7 (3 samples sample 21, 22, 25) and Brand 8 (2 samples sample 9, 20). The details of sample collection is presented in Table 1 .

\section{Moisture content in cattle feed samples}

The moisture content of the cattle feed samples varied from $7.0 \%$ to $14.6 \%$ with an average of $10.34 \%$. The lowest moisture content percentage was observed in samples 2, 5, 9 and 15 as $7.0 \%$ and the highest moisture content was observed in samples 12 and 13 as $14.6 \%$. The details of moisture content from individual samples were presented in Table 1 and Fig. 1.

\section{Storage fungi}

The storage fungi mainly comprising different species of Aspergillus and Pencillium were encountered in cattle feed samples in varying numbers. Few other fungi like Mucor, Rhizophus, Pyricularia, Helminthosporium and cladosporium also were observed in very less numbers in cattle feed sampes. The following individual species of Aspergillus and Penicillium were observed.
1. Aspergillus niger
2. A. glaucus
3. A. flavus
4. A. terreus
5. A. nidulans
6. A. fumigates
7. A. candidus
8. Penicillium citrinum
9. P. Funiculosum
10. P. Chrysogenum
11. P. tardum
12. Mucor mucedo
13. Rhizophus stolonifer
14. Pyricularia oryzae

The overall population of storage fungi in individual cattle feed samples is observed as in the range of 600 to $1600 \mathrm{cfu} / \mathrm{g}$ with an average of $950 \mathrm{cfu} / \mathrm{g}$. Among the above species of fungi, Aspergillus glaucus observed very frequently in samples and dominance in samples in the range of 0 to $1,600 \mathrm{cfu} / \mathrm{g}$ with an average of $340 \mathrm{cfu} / \mathrm{g}$. followed by A. terreus, Penicillium citrinum and A. fumigatus occurred in less numbers. However, the overall population of storage fungi is observed to be very less when compared with the population of various rice bran samples in our earlier studies which are one of the raw material for formulation of cattle feed. Our earlier studies shows the occurrence of storage fungi in rice bran and de-oiled rice bran in higher numbers as up to 
$1,30,000 \mathrm{cfu} / \mathrm{g}$ with an average of 33,000 cfu/g which include toxigenic A. flavus (Jayaraman and Kalyanasundaram, 2009; Jayaraman, 1991). The details were presented in Table 2 and Fig. 2.

\section{Aflatoxins}

Out of 25 cattle feed samples analysed, 20 samples were found positive results for aflatoxin $B_{1}$. Five samples were found free of contamination with aflatoxin $\mathrm{B}_{1}$. The concentration of aflatoxin $\mathrm{B}_{1}$ in different cattle feed samples varying in the range from $5 \mathrm{ppb}$ to $110 \mathrm{ppb}$ with an average of $22 \mathrm{ppb}$. Of the 25 samples from 8 brands of cattle feed analysed, the samples 4, 8, 9, 15 and 24 showed negative for aflatoxin $B_{1}$.

Table.1 Details of moisture content (\%) of cattle feed samples

\begin{tabular}{|c|l|l|l|c|}
\hline S. No. & $\begin{array}{c}\text { Name of the } \\
\text { sample }\end{array}$ & \multicolumn{1}{|c|}{$\begin{array}{c}\text { Place of } \\
\text { Collection }\end{array}$} & District Name & $\begin{array}{c}\text { Moisture } \\
\text { Content } \\
(\%)\end{array}$ \\
\hline 1 & Sample 1 & MM Nagar & Kancheepuram & 9.6 \\
\hline 2 & Sample 2 & Chengalpet & Kancheepuram & 7.0 \\
\hline 3 & sample 3 & Maduranthagam & Kancheepuram & 8.8 \\
\hline 4 & Sample 4 & Chengalpet & Kancheepuram & 10.8 \\
\hline 5 & Sample 5 & Uthiramerur & Kancheepuram & 7.0 \\
\hline 6 & Sample 6 & Thiruvallur & Thiruvallur & 9.4 \\
\hline 7 & Sample 7 & Palamarathur & Thiruvannamala & 8.2 \\
\hline 8 & Sample 8 & Palamarathur & Thiruvannamala & 9.0 \\
\hline 9 & Sample 9 & Kattangulathur & Kancheepuram & 7.0 \\
\hline 10 & Sample 10 & MM Nagar & Kancheepuram & 8.6 \\
\hline 11 & Sample 11 & Uthiramerur & Kancheepuram & 12.4 \\
\hline 12 & Sample 12 & Uthiramerur & Kancheepuram & 14.6 \\
\hline 13 & Sample 13 & Chetpet & Thiruvannamalai & 14.6 \\
\hline 14 & Sample 14 & Manalurpet & Villupuram & 13.2 \\
\hline 15 & Sample 15 & Gingee & Villupuram & 7.0 \\
\hline 16 & Sample 16 & Gingee & Villupram & 12.2 \\
\hline 17 & Sample 17 & Chetpet & Thiruvannamalai & 10.4 \\
\hline 18 & Sample 18 & Chetpet & Thiruvannamalai & 13.2 \\
\hline 19 & Sample 19 & Chengalpet & Kancheepuram & 8.6 \\
\hline 20 & Sample 20 & Kattankolathur & Kancheepuram & 12.6 \\
\hline 21 & Sample 21 & Madhuranthagam & Kancheepuram & 10.4 \\
\hline 22 & Sample 22 & Madhuranthagam & Kancheepuram & 10.6 \\
\hline 23 & Sample 23 & Palamarathur & Thiruvannamalai & 11.6 \\
\hline 24 & Sample 24 & Palamarathur & Thiruvannamalai & 12.8 \\
\hline 25 & Sample 25 & Palamarathur & Thiruvannamalai & 8.8 \\
\hline & & & & \\
\hline
\end{tabular}


Table.2 Occurrence of storage fungi and toxigenic fungi in cattle feed samples

\begin{tabular}{|c|c|c|c|c|c|c|}
\hline S. No. & $\begin{array}{c}\text { Name of the } \\
\text { sample }\end{array}$ & $\begin{array}{l}\text { Place of } \\
\text { Collection }\end{array}$ & $\begin{array}{l}\text { Total No. of } \\
\text { Storage fungi } \\
\text { (CFU/g) }\end{array}$ & A. flavus & $\begin{array}{c}\text { Afla- } \\
\text { toxigenic } \\
\text { A.flavus }\end{array}$ & A. glacus \\
\hline 1 & Sample 1 & MM Nagar & 1600 & 400 & + & 1000 \\
\hline 2 & Sample 2 & Chengalpet & 1200 & 0 & - & 500 \\
\hline 3 & sample 3 & Maduranthagam & 600 & 200 & - & 0 \\
\hline 4 & Sample 4 & Chengalpet & 800 & 0 & - & 200 \\
\hline 5 & Sample 5 & Uthiramerur & 1000 & 0 & - & 500 \\
\hline 6 & Sample 6 & Thiruvallur & 1200 & 0 & - & 600 \\
\hline 7 & Sample 7 & Palamarathur & 900 & 0 & - & 0 \\
\hline 8 & Sample 8 & Palamarathur & 800 & 0 & - & 200 \\
\hline 9 & Sample 9 & Kattangulathur & 1100 & 900 & + & 0 \\
\hline 10 & Sample 10 & MM Nagar & 700 & 200 & - & 0 \\
\hline 11 & Sample 11 & Uthiramerur & 1000 & 0 & - & 0 \\
\hline 12 & Sample 12 & Uthiramerur & 900 & 200 & - & 200 \\
\hline 13 & Sample 13 & Chetpet & 500 & 200 & + & 100 \\
\hline 14 & Sample 14 & Manalurpet & 1000 & 200 & - & 0 \\
\hline 15 & Sample 15 & Gingee & 1200 & 0 & - & 200 \\
\hline 16 & Sample 16 & Gingee & 1600 & 0 & - & 1000 \\
\hline 17 & Sample 17 & Chetpet & 1000 & 300 & + & 600 \\
\hline 18 & Sample 18 & Chetpet & 600 & 200 & + & 300 \\
\hline 19 & Sample 19 & Chengalpet & 1600 & 0 & - & 1600 \\
\hline 20 & Sample 20 & Kattankolathur & 800 & 0 & - & 600 \\
\hline 21 & Sample 21 & Madhuranthagam & 500 & 0 & - & 500 \\
\hline 22 & Sample 22 & Madhuranthagam & 600 & 0 & - & 500 \\
\hline 23 & Sample 23 & Palamarathur & 600 & 0 & - & 0 \\
\hline 24 & Sample 24 & Palamarathur & 800 & 0 & - & 0 \\
\hline 25 & Sample 25 & Palamarathur & 1100 & 0 & - & 400 \\
\hline
\end{tabular}


Table.3 Occurrence of aflatoxin B1 in different cattle feed samples

\begin{tabular}{|c|c|c|c|c|}
\hline \multirow[b]{2}{*}{ S. No. } & \multirow{2}{*}{$\begin{array}{c}\text { Name of the } \\
\text { sample }\end{array}$} & \multirow[b]{2}{*}{ Place of Collection } & \multicolumn{2}{|c|}{ Aflatoxin analysis } \\
\hline & & & Qualitative & $\begin{array}{l}\text { Quantitative } \\
\text { (PPb) }\end{array}$ \\
\hline 1 & Sample 1 & MM Nagar & + & 5 \\
\hline 2 & Sample 2 & Chengalpet & + & 5 \\
\hline 3 & Sample 3 & Maduranthagam & + & 5 \\
\hline 4 & Sample 4 & Chengalpet & - & Not detected \\
\hline 5 & Sample 5 & Uthiramerur & + & 10 \\
\hline 6 & Sample 6 & Thiruvallur & + & 25 \\
\hline 7 & Sample 7 & Palamarathur & + & 10 \\
\hline 8 & Sample 8 & Palamarathur & - & Not detected \\
\hline 9 & Sample 9 & Kattangulathur & - & Not detected \\
\hline 10 & Sample 10 & MM Nagar & + & 10 \\
\hline 11 & Sample 11 & Uthiramerur & + & 15 \\
\hline 12 & Sample 12 & Uthiramerur & + & 15 \\
\hline 13 & Sample 13 & Chetpet & + & 20 \\
\hline 14 & Sample 14 & Manalurpet & + & 5 \\
\hline 15 & Sample 15 & Gingee & - & Not detected \\
\hline 16 & Sample 16 & Gingee & + & 50 \\
\hline 17 & Sample 17 & Chetpet & + & 15 \\
\hline 18 & Sample 18 & Chetpet & + & 5 \\
\hline 19 & Sample 19 & Chengalpet & + & 60 \\
\hline 20 & Sample 20 & Kattankolathur & + & 10 \\
\hline 21 & Sample 21 & Madhuranthagam & + & 110 \\
\hline 22 & Sample 22 & Madhuranthagam & + & 50 \\
\hline 23 & Sample 23 & Palamarathur & + & 10 \\
\hline 24 & Sample 24 & Palamarathur & - & Not detected \\
\hline 25 & Sample 25 & Palamarathur & + & 5 \\
\hline
\end{tabular}

+ Positive result; - Negative result 


\section{Int.J.Curr.Microbiol.App.Sci (2017) 6(2): 1853-1863}

Fig.1 Details of moisture content (\%) of cattle feed samples

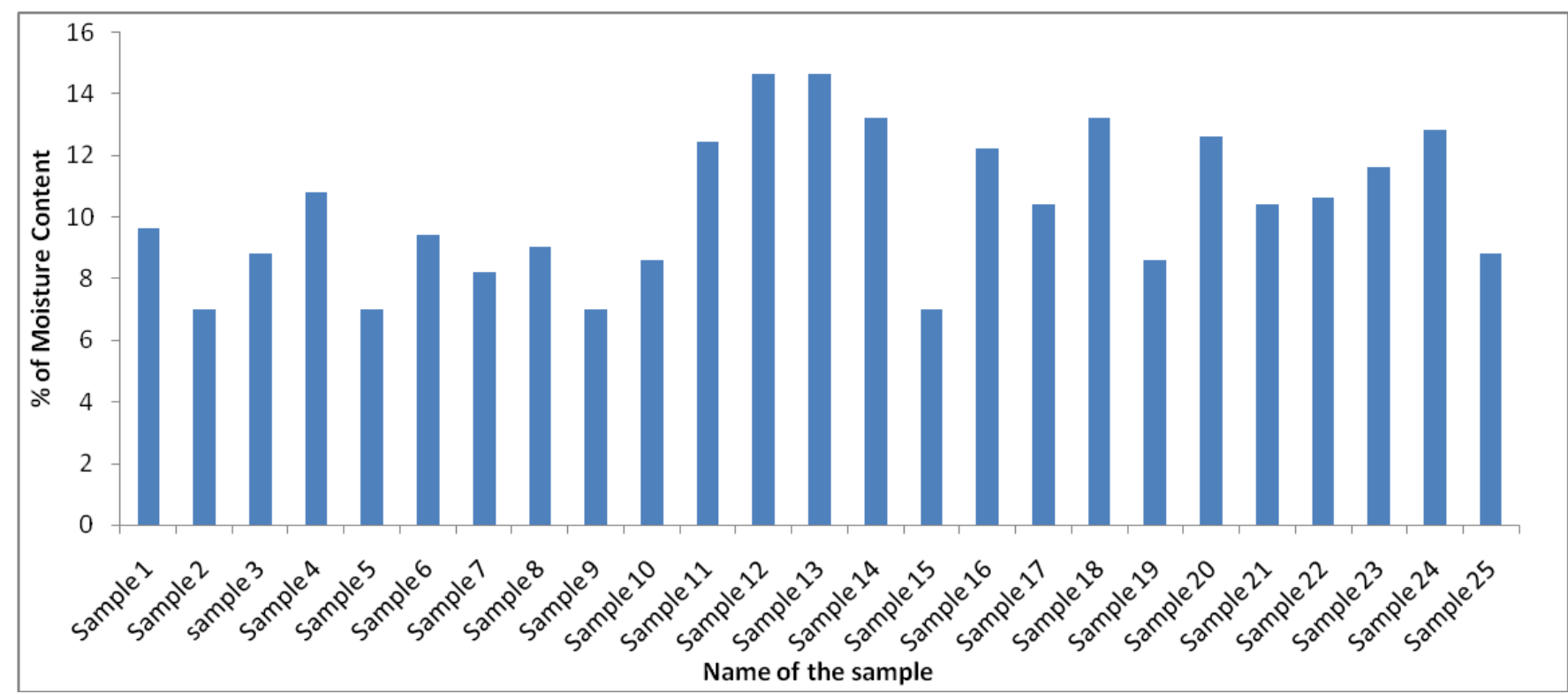

Fig.2 Occurrence of storage fungi and toxigenic fungi in cattle feed samples

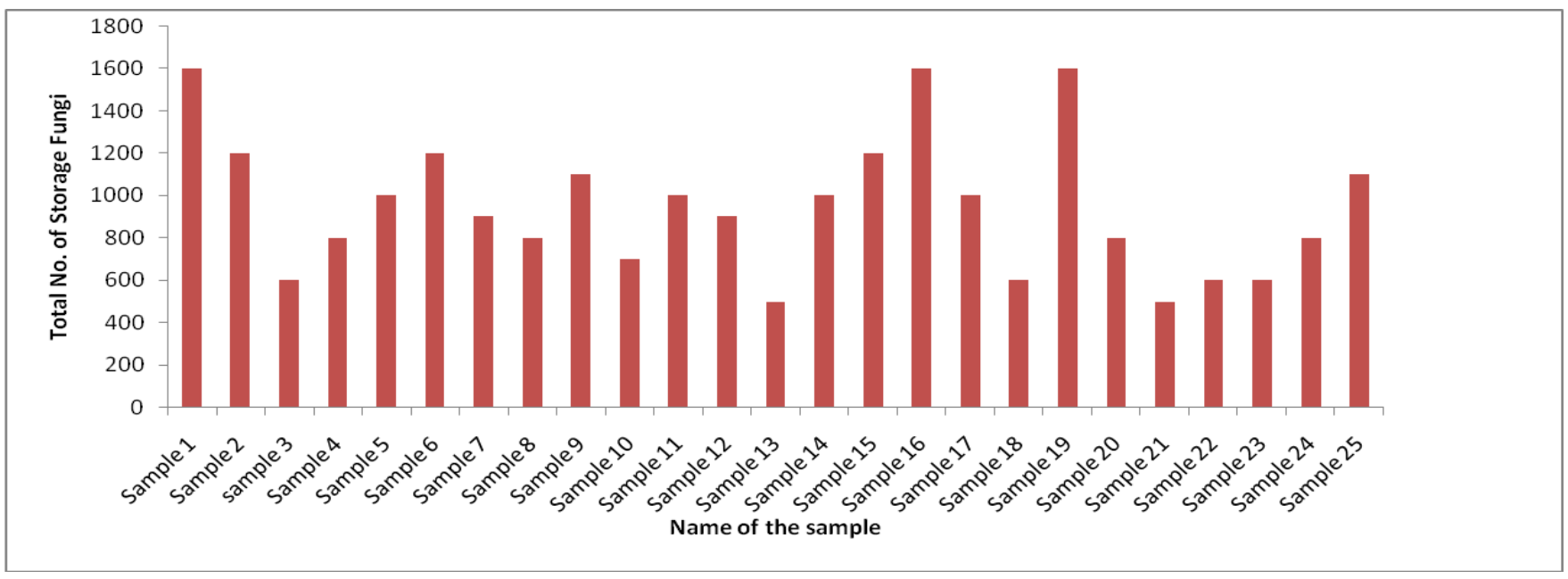


Among the samples found positive for aflatoxins, samples 16, 19, 21 and 22 showed slightly higher concentration $(50 \mathrm{ppm}, 60$ ppm, $110 \mathrm{ppm}$ and $50 \mathrm{ppm}$ respectively) and other samples show very lower concentration. These differences might be due to the presence aflatoxin contamination in raw materials used for formulation of cattle feed and the processing parameters. Contamination of deoiled rice bran and carttle feed samples with higher level of aflatoxins in our earlier studies (Jayaraman and Kalyanasundaram, 2009,; Jayaraman and Kalyanasundaram 1994, Jayaraman, 1991) is not comparable to the cattle feed samples of the present study which might be due to the advancement of processing technology in cattlefeed manufacturing as well as raw material quality. However, the lower concentration or absence of aflatoxin $B_{1}$ in cattle feed samples will yield very lower level of occurrence in milk samples due to the metabolic degradation of aflatoxins in dairy animals. The occurrence of distribution of aflatoxin $B_{1}$ in cattle feed samples were presented in Table 3.

\section{Toxigenic fungi}

Out of 25 cattle feed samples analysed for the storage fungi, only 9 samples were found contaminated with of Aspergillus flavus a lower population as $100 \mathrm{cfu} / \mathrm{g}$ to $300 \mathrm{cfu} / \mathrm{g}$ of sample (sample 1, sample 3, sample 9, sample 10, 12, 13, 14, 17 and 18). Out of 9 strains of A. flavus, only 4 strains (sample 1, sample 9, sample 13, sample 17 and 18 respectively) were found to produce aflatoxins $\mathrm{B}_{1}$ (Table 3 ). This indicates that the cattle feed samples show mostly free of contamination with $A$. flavus species. However in the previous studies of Jayaraman and Kalyanasundaram, 2009 and Jayaraman and Kalyanasundaram, 1990, more than $60 \%$ of A. flavus strains isolated from rice bran and de-oiled bran samples were positive for aflatoxin production. The lower occurrence and less toxigenci $A$. flvus this might be due to the physical and chemical parameters involve in the treatments during processing of manufacture.

In conclusion, the present study revealed that the presence of aflatoxin $B_{1}$ in most of the cattle feed samples available in the compounded form at lower concentration as safer level except very few samples. The population of storage fungi including Aspergillus and Pencillium species also was observed to be very low when compared with raw materials used for formulation before processing. The remarkable finding of the present study is thelowe incidence of aflatoxin producing Aspergillus flavus in cattle feed samples which indicate the further contamination is seldom possible even during storage of cattle feed. Based on the above results it is found most of the cattle feed samples available in the market is contaminated with permissible limit of aflatoxin $B_{1}$ which even possible to reduce further after deriving in to milk durig metabolic degradation in cow. However, survey work of the above is undergoing and the final conclusion could be obtained after making large number of samples by using ELISA technique.

\section{Acknowledgements}

University Grant Commission (UGC) is highly acknowledged for the research grant sanctioned with reference to the UGC-MRP No.43-141/2014(SR) dt. 23.07.2015 to carry out the above research programme.

\section{References}

Banumathy and Indira Kalyanasundaram.1986. Contamination of rice with storage fungi from therice field environment. J. Madras Univ. 49, 
45-72.

Bhat R, Rai RV and Karim AA.2010. Mycotoxins in Food and Feed: Present Status and Future Concerns. Comprehen. Rev. Food Sci. \& Food Saf. 9, 57-81.

Bilgrami KS, Prasad T, Mishra RS and Sinha KK.1980. Survey and study of mycotoxin producing fungi associated with grains in the standing maize crop. Final technical Report, ICAR Project, Bhagalpur University.

Bullerman L.1974. Inhibition of aflatoxin production by cinnamon. J. Food Sci. 39, 1163-1165.

European commission, Health and consumers directorate-general.2011. Directorate f - food and veterinary office DG.Sanco. 2010-8597 - MR final, Final report of a mission carried out in India from 10 to 18 november 2010 in order to assess the control system in place to control aflatoxin contamination in basmati rice intended for export to the European Union, Ref. Ares.2011.520060 13/05/2011.

Gajapathy N and Kalyanasundaram.1986. Distribution of rice seed mycoflora within the grains with special reference to storage ffungi. Indian Phytopath. 39, 288-292.

Jayaraman P and Kalyanasundaram I.1994. A comparison of bran from parboiled and raw rice. Ind. Phytopath. 47, 147-152.

Jayaraman P and Kalyanasundaram I.1994. Storage mycoflora of parboiled rice through the different stages of processing. J. Food. Sci. Tech. 31, 219224.

Jayaraman P and Kalyanasundaram I.2009. Natural Occurrence of Aflatoxins and toxigenic fungi in Rice bran oil and Deoiled bran. Ind. J. Sci. and Technol. 2.10., 35-37.

Jayaraman P and Kalyanasundaram I.1990. Natural occurrence of toxigenic fungi and mycotoxins in rice bran. Mycopathologia. 110, 81-85.

Jayaraman P and Kalyanasundaram I.1994. Changes in moisture content, mycoflora and aflatoxin content of rice branduring storage. Mycopathologia. 126, 115-121.

Johanna fink-gremmels.2008. Mycotoxins in cattle feeds and carry-over to dairy milk: Food Additives \& Contaminants. 25.2., 172-180.

Kang'ethe EK and Lang'a KA.2009. Aflatoxin B1 and M1 contamination of animal feeds and milk from urban centers in Kenya, Afr Health Sci. 9.4., 218-226.

Korrapati K, Mohanamba $\mathrm{T}$ and Rathna Kumari L.2015. Assessment of aflatoxin B1 in livestock feed and feed ingredients by high-performance thin layer chromatography. Vet World. 8.12., 1396-1399.

Nabney $\mathbf{J}$ and Nesbitt BF.1965. A spectrophotometric method for determining the aflatoxin, Analyst. 90, 155-160.

Oranusi SU and Olarewaju SA.2013. Int. J. Biotech. \& Allied Fields. 1.1., 9-18.

Rao GJ and Kalyanasundram I.1983. Osmophilism in food grain storage fungi. Mycopathologia, 83, 3-7.

Reddy KRN, Reddy CS, Abbas HK, Abel CA and Muralidharan K.2008. Mycotoxigenic fungi, mycotoxins, and management of rice grains. 27, 287-317.

Seitz IM and Mohr HW.1977. New method for quantification of aflatoxin in corn. Cerela Chem. 54, 179-183

Toteja GS, Mukherjee A, Diwakar S, Singh P, Saxena BN, Sinha KK, Sinha AK, Kumar N, Nagaraja KV, Bai G, Prasad CA, Vanchinathan S, Roy R and Parkar S. 2006. Aflatoxin B1 contamination in wheat grain samples collected from different geographical regions of India: A multicenter study. J Food Prot. 69, 1463-1467. 
Upadhaya SD, Park MA and Ha JK.2010. Mycotoxins and Their Biotransformation in the Rumen: A Review. Asian-Australasian J. Animal Sci. 23, 1250-1260,1011-2367.

Vasanthi Siruguri.2012. Aflatoxin contamination in stored rice variety PAU 201 collected from Punjab, India, Indian J Med Res. 136, 89-97.

Vincent Paul Ilangovan.1999. Studies on aflatoxin production in rice: A Focus on varietal differences on contamination. $\mathrm{Ph}$.D. Thesis, University of Madras.

Waliyar F and Reddy SV.2009. Aspergillu flavus seed infection and aflatoxin estimation by ELISA and aflatoxin management options in groundnut in Training Manual by International Crops Research Institute.ICRISAT.

Whitlow LW and Hagler WM, Mold JR and Mycotoxin Issues in Dairy Cattle: Effects, Prevention and Treatment, Dairy, September 23, 2016.

Wu F, Liu Y and Bhatnagar D.2008. Costeffectiveness of aflatoxin control methods: economic incentives. Informa Healthcare 27, 203-225.

Wu F.2006. Mycotoxin reduction in Bt corn: potential economic, health, and regulatory impacts. Transgenic Res., 15 , 277-289.

\section{How to cite this article:}

Jayaraman, P., V. Rajesh and Vadamalai Krishnan, K. 2017. Analysis of Formulated CattleFeed Samples for the Natural Occurrence of Storage Fungi and Aflatoxin B1. Int.J.Curr.Microbiol.App.Sci. 6(2): 1853-1863. doi: http://dx.doi.org/10.20546/ijcmas.2017.602.209 